\title{
High dose rate and flattening filter free irradiation can be safely implemented in clinical practice
}

Citation for published version (APA):

Dubois, L., Biemans, R., Reniers, B., Bosmans, G., Trani, D., Podesta, M., Kollaard, R., Rouschop, K. M. A., Theys, J., Vooijs, M., Pruschy, M., Verhaegen, F., \& Lambin, P. (2015). High dose rate and flattening filter free irradiation can be safely implemented in clinical practice. International Journal of Radiation Biology, 91(10), 778-785. https://doi.org/10.3109/09553002.2015.1068457

Document status and date:

Published: 03/10/2015

DOI:

10.3109/09553002.2015.1068457

Document Version:

Publisher's PDF, also known as Version of record

Document license:

Taverne

\section{Please check the document version of this publication:}

- A submitted manuscript is the version of the article upon submission and before peer-review. There can be important differences between the submitted version and the official published version of record.

People interested in the research are advised to contact the author for the final version of the publication, or visit the DOI to the publisher's website.

- The final author version and the galley proof are versions of the publication after peer review.

- The final published version features the final layout of the paper including the volume, issue and page numbers.

Link to publication

\footnotetext{
General rights rights.

- You may freely distribute the URL identifying the publication in the public portal. please follow below link for the End User Agreement:

www.umlib.nl/taverne-license

Take down policy

If you believe that this document breaches copyright please contact us at:

repository@maastrichtuniversity.nl

providing details and we will investigate your claim.
}

Copyright and moral rights for the publications made accessible in the public portal are retained by the authors and/or other copyright owners and it is a condition of accessing publications that users recognise and abide by the legal requirements associated with these

- Users may download and print one copy of any publication from the public portal for the purpose of private study or research.

- You may not further distribute the material or use it for any profit-making activity or commercial gain

If the publication is distributed under the terms of Article $25 \mathrm{fa}$ of the Dutch Copyright Act, indicated by the "Taverne" license above, 


\section{High dose rate and flattening filter free irradiation can be safely implemented in clinical practice}

Ludwig Dubois, Rianne Biemans, Brigitte Reniers, Geert Bosmans, Daniela Trani, Mark Podesta, Robert Kollaard, Kasper ma Rouschop, Jan Theys, Marc Vooijs, Martin Pruschy, Frank Verhaegen \& Philippe Lambin

To cite this article: Ludwig Dubois, Rianne Biemans, Brigitte Reniers, Geert Bosmans, Daniela Trani, Mark Podesta, Robert Kollaard, Kasper ma Rouschop, Jan Theys, Marc Vooijs, Martin Pruschy, Frank Verhaegen \& Philippe Lambin (2015) High dose rate and flattening filter free irradiation can be safely implemented in clinical practice, International Journal of Radiation Biology, 91:10, 778-785, DOI: 10.3109/09553002.2015.1068457

To link to this article: https://doi.org/10.3109/09553002.2015.1068457

+ View supplementary material $\longleftarrow$

Submit your article to this journal ๘

View related articles $\llbracket$

Citing articles: 4 View citing articles $\sqsubset$
Published online: 28 Aug 2015.

Џ Article views: 246

View Crossmark data \ulcorner 


\title{
High dose rate and flattening filter free irradiation can be safely implemented in clinical practice
}

\author{
Ludwig Dubois ${ }^{1}$, Rianne Biemans ${ }^{1}$, Brigitte Reniers ${ }^{1}$, Geert Bosmans ${ }^{1}$, Daniela Trani ${ }^{1}$, Mark Podesta ${ }^{1}$, \\ Robert Kollaard ${ }^{1}$, Kasper MA Rouschop ${ }^{1}$, Jan Theys ${ }^{1}$, Marc Vooijs ${ }^{1}$, Martin Pruschy ${ }^{2}$, \\ Frank Verhaegen ${ }^{1} \&$ Philippe Lambin ${ }^{1}$ \\ ${ }^{1}$ Department of Radiation Oncology (MAASTRO), GROW - School for Oncology and Developmental Biology, Maastricht \\ University Medical Centre, Maastricht, the Netherlands, and ${ }^{2}$ Department of Radiation Oncology, University Hospital Zurich, \\ Zurich, Switzerland
}

\begin{abstract}
Purpose: We hypothesize that flattening filter free (FFF) high dose rate irradiation will decrease cell survival in normal and cancer cells with more pronounced effects in DNA repair deficient cells. Additionally, we hypothesize that removal of the flattening filter will result in an enhanced relative biological effectiveness independent of the dose rate.

Materials and methods: Clonogenic survival was assessed after exposure to dose rates of 4 or $24 \mathrm{~Gy} / \mathrm{min}$ (FFF 10 megavolt [MV] photon beam) using a Varian TrueBeam accelerator. Additionally, cells were exposed to $4 \mathrm{~Gy} / \mathrm{min}$ with or without flattening filter. Relative biological effectiveness estimations were performed comparing the different beam photon spectra.

Results: Cell survival in tumor and normal cell lines was not influenced by high dose rate irradiation. The intrinsic radiation sensitivity of DNA repair deficient cells was not affected by high dose rate compared to normal dose rate. Furthermore, the relative biological effectiveness was not significantly different from unity in any of the cell lines for both FFF and conventional flattened beam exposures.

Conclusions: High dose rate irradiation did not affect long-term survival and DNA repair for cell lines of different tissues. This suggests that high dose rate does not influence treatment outcome or treatment toxicity and could be safely implemented in clinical routine.
\end{abstract}

Keywords: High dose rate irradiation, flattening filter free (FFF), cell survival, DNA repair

\section{Introduction}

Recently evolved techniques within radiation oncology, such as intensity-modulated radiation therapy (IMRT), result in better dose conformity to tumors with increasing sparing of healthy tissues. This is realized through modification of the dose rate as well as the beam shape, while accepting more monitor units, an increased out-of-field dose volume and longer delivery times (Wang et al. 2003). Volumetricmodulated arc therapy (VMAT) shortens overall treatment time using dynamically modulated arc beams which dispenses of flattening filters. Flattening filter free (FFF) beams can deliver higher instantaneous dose rates with reduced head scatter, increased beam stability and lower out-of-field dose (Georg et al. 2011). Removing the flattening filter causes a softer energy spectrum in the center of the radiation field (Verhaegen and Seuntjens 2003). The lower photon energy results in lower energy electrons, which theoretically may cause more biological damage, i.e., provide a higher relative biological effectiveness (RBE) (Liu and Verhaegen 2002, Kirkby et al. 2007, Syme et al. 2009).

For low dose rates, ionizing irradiation does affect cellular survival (Bedford and Mitchell 1973). Data on the actual radiobiological consequences of these high dose rates using FFF beams show conflicting results. Higher instantaneous dose rate beams have been shown to reduce clonogenic cell survival in some studies (Lohse et al. 2011), while no differences were observed in others (Sorensen et al. 2011, Karan et al. 2013, King et al. 2013, Verbakel et al. 2013, Lasio et al. 2014). Before safely implementing FFF irradiation in the clinic, more research is needed to resolve these reported discrepancies obtained using different cell lines and experimental settings. DNA repair of sublethal damage determines the outcome of dose rate experiments (Steel et al. 1987, Lambin and Wouters 2004) and more residual DNA damage is present upon high dose rate (HDR) irradiation in repair-deficient cells ( $\mathrm{Hu}$ and Hill 1996). Additionally, cells deficient for homologous recombination $(\mathrm{HR})$ often have a lower alpha/beta $(\alpha / \beta)$ ratio and are more sensitive for high dose per fraction.

Correspondence: Dr Ludwig Dubois, Department of Radiation Oncology (MAASTRO Lab), GROW - School for Oncology and Developmental Biology, Maastricht University Medical Centre, UNS 50/23, PO Box 616, 6200 MD Maastricht, The Netherlands. Tel: + 31 (0)43 3882909 . Fax: + 31 (0)43 3884540. E-mail: ludwig.dubois@maastrichtuniversity.nl

(Received 21 November 2014; revised 29 May 2015; accepted 24 June 2015) 
Therefore, we hypothesize that FFF high dose rate irradiation will decrease cell survival in normal and cancer cells and this effect will be more pronounced for HR DNA repair deficient cell lines. Since the RBE is believed to correlate with radiobiological damage (Goodhead 1994), we also hypothesize that flattening filter (FF) removal will result in an enhanced RBE independently of the dose rate.

\section{Methods}

\section{Cell culture}

Exponentially growing human lung (A549, ATCC CCL-185), breast (MCF7, ATCC HTB-22) and brain (U373 MG, ATCC HTB-17) carcinoma cells and human lung (NL20, ATCC CRL2503) and breast (MCF10A, ATCC CRL-10317) immortalized non-tumorigenic epithelial cells were cultured in the appropriate medium, as described by ATCC, supplemented with $10 \%$ fetal bovine serum (FBS) (Greiner Bio-One B.V., Alphen a/d Rijn, The Netherlands). The Human DNA repair deficient colon (HCT116 parental and DNA-dependent protein kinase, catalytic subunit [DNA-PKcs-/-] non-homologous end joining [NHEJ] deficient, HD PAR-082 and HD R02-049) and colorectal (DLD1 parental and breast cancer 2, early onset [BRCA2-/-] homologous recombination [HR] deficient, HD PAR-008 and HD 105-007) carcinoma cells were cultivated as recommended by the supplier (Horizon Discovery Ltd, Cambridge, UK). Chinese hamster ovary cells (CHO9 wild type [wt], CHO9 X-ray repair complementing protein 1 [XR-Cl] DNA-PKcs-/- NHEJ deficient, CHO9 derivative AA8 wt, AA8 ionizing irradiation sensitive clone 1sf [IRS1sf] X-ray repair cross-complementing protein 3 [XRCC3-/-] HR deficient and AA8 ultraviolet sensitive mutant 5 [UV5] xeroderma pigmentosum D orthologue [XPD-/-] nucleotide excision repair [NER] deficient) were cultured in Ham's F-10 medium (Lonza Benelux B.V., Breda, The Netherlands), supplemented with $10 \%$ FBS.

\section{Treatment planning}

A CT (Siemens Biograph 40, Siemens Healthcare, Malvern, PA, USA) scan (slice thickness $1 \mathrm{~mm}$ ) of the experimental set-up was made for accurate treatment planning (Figure 1). 10 megavolt (MV) FF beams were delivered at a dose rate of $4 \mathrm{~Gy} / \mathrm{min}, 10 \mathrm{MV} \mathrm{FFF}$ beams at 4 or $24 \mathrm{~Gy} / \mathrm{min}$ using a Varian TrueBeam accelerator (Varian Medical Systems, Palo Alto, CA, USA). For FF beams, the dose per pulse at the depth of the maximum dose $\left(\mathrm{d}_{\max }\right)$ was found to be 0.03 and $0.056 \mathrm{cGy} /$ pulse, respectively, for low and high dose rate $10 \mathrm{MV}$ photon beams. The dose per pulse at $\mathrm{d}_{\max }$ for $10 \mathrm{MV}$ FFF beams equals $0.13 \mathrm{cGy} /$ pulse and was found to be independent of the nominal dose rate (Kry et al. 2012). For each uniform dose level, treatment planning was performed with the Anisotropic Analytical Algorithm (AAA [10.0.28], Eclipse, Varian Medical Systems) calculation model with a dose calculation grid resolution of $1 \mathrm{~mm}$. Polymethylmetacrylate (PMMA, $2 \mathrm{~cm}$ ) dose build-up was used for calculations and irradiation. Surface (cells) source distance was kept at $96.4 \mathrm{~cm}$ for both beam schedules. FF and FFF beams were delivered using a $20 \times 20 \mathrm{~cm}$ or $8 \times 8 \mathrm{~cm}$ irradiation field respectively, with the center of jig (FF) or the center of the dish (FFF) at the isocenter of the beam. This setup resulted in 88.6 and 102.8 monitor units per Gy for FF and FFF beams, respectively.

\section{Dose verification}

The delivered dose was verified using circular pieces (35-40 mm diameter) of Gafchromic ${ }^{\circledR}$ EBT3 films (Ashland Specialty Ingredients, Wayne, NJ, USA), cut to fit the dishes for a 2 Gy delivery. The films were placed at the bottom of the dishes using the same experimental set-up as described above. The film batch was calibrated in the beam used for the cell experiments. Each piece of film was scanned at the same time as a test piece irradiated at a known dose to validate the absolute dose measurements. Absolute dosimetry was validated by the ratios of the measured doses to the calculated doses for the test films which were $0.7 \%$ for the FF scan and $1.2 \%$ for FFF scan. The average delivered dose on an $80 \%$ area of the dish was found to be $196 \pm 3.9 \mathrm{cGy}$ and $203.1 \pm 14.9 \mathrm{cGy}$ for the FF and FFF beam respectively (Figure 1C). The area profiles obtained from the film measurements at the position of the cells are compared to the planned doses using difference maps (Figure 1C). For FF irradiation, $76.3 \%$ of the pixels measured with the film are within $3 \%$ of the planned dose, while for FFF irradiation this was found to be $90.2 \%$

\section{Irradiation and clonogenic survival}

Exponentially growing cells were cultivated in dishes until $70 \%$ confluency was reached. Subsequently, cells were irradiated $(0,2,5$ or $10 \mathrm{~Gy})$ with or without flattening filter according to the treatment planning described above. To ensure an adequate number of colonies, irradiation dose within our study was limited to $10 \mathrm{~Gy}$, since cell survival probability is too low for higher dose levels. Afterwards, cells were trypsinized and plated in triplicate for clonogenic survival. Cells were allowed to form colonies for 10-14 days, the day on which they were fixed and stained with $0.4 \%$ methylene blue in $70 \%$ ethanol. Afterwards, colonies were counted manually and survival was calculated by dividing the number of colonies ( $>50$ cells) by the number of seeded cells, corrected for the plating efficiency of the non-irradiated cells. The survival plots were fitted using the linear-quadratic model.

\section{Calculation of Relative Biological Effectiveness (RBE)}

RBE for DNA double-strand break (DSB) induction was calculated in a three-step procedure (Reniers et al. 2008). First, Monte Carlo simulations were used to obtain primary electron distributions in water. $10 \mathrm{MV}$ FF and FFF photon distributions emitted by the linear accelerator were obtained from the manufacturer (Varian Medical Systems). These were used as input for Monte Carlo simulations with the Electron Gamma Shower from the National Research Council of Canada (EGSnrc) code (Kawrakow 2000). Sampled photons were transported in water to a depth of 0.5 $\mathrm{cm}$ where the primary electrons were scored. Contaminant electrons from the accelerator were neglected. To ensure the production of Compton electrons below 1 kile electron volt $(\mathrm{keV})$, the photon and electron production cut-offs were set to $100 \mathrm{eV}$. Second, the Monte Carlo Damage Simulation program (Hsiao and Stewart 2008) was used for calculation of distributions of clustered DNA lesions such as DSB. Third, 
(A)
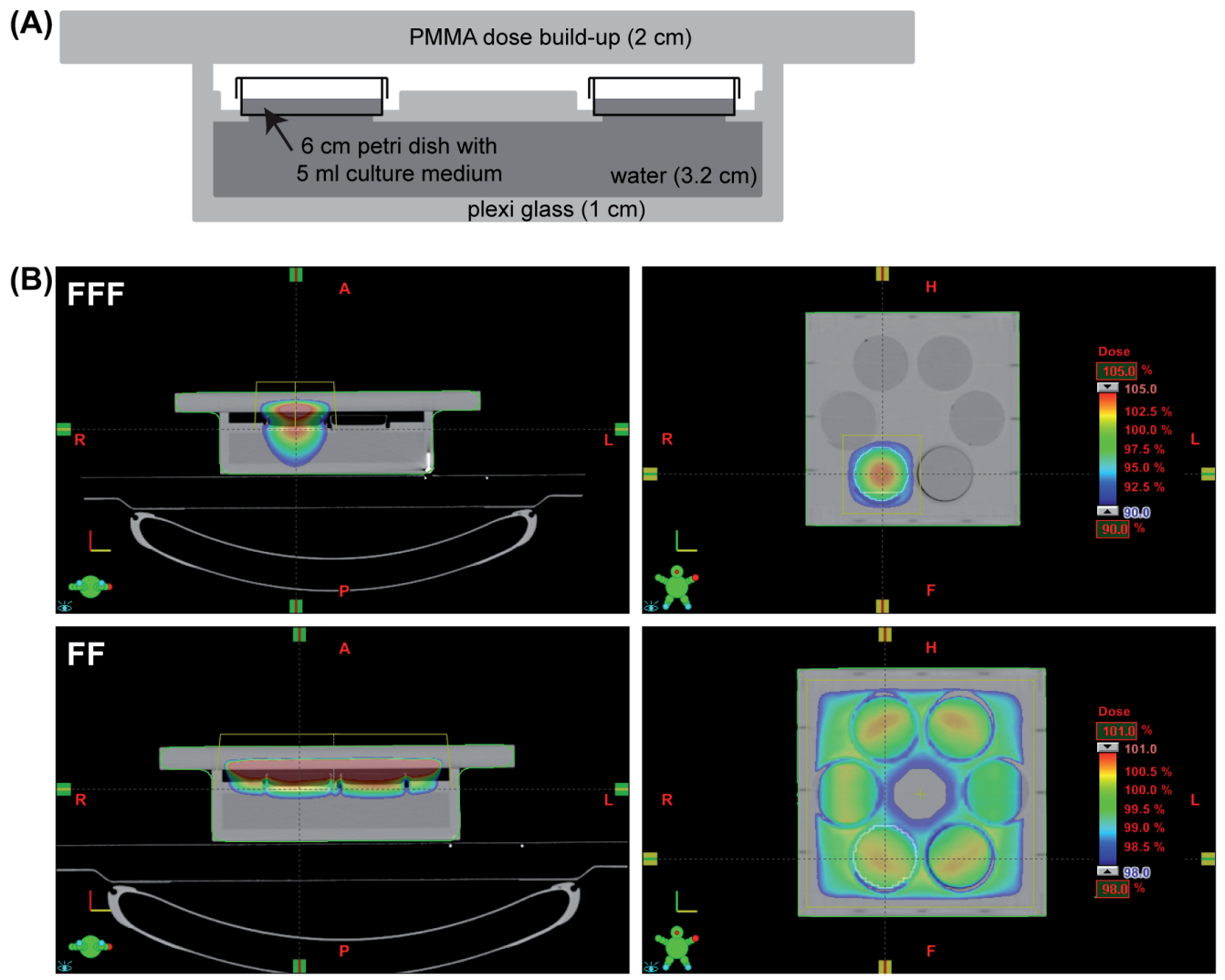

(C)
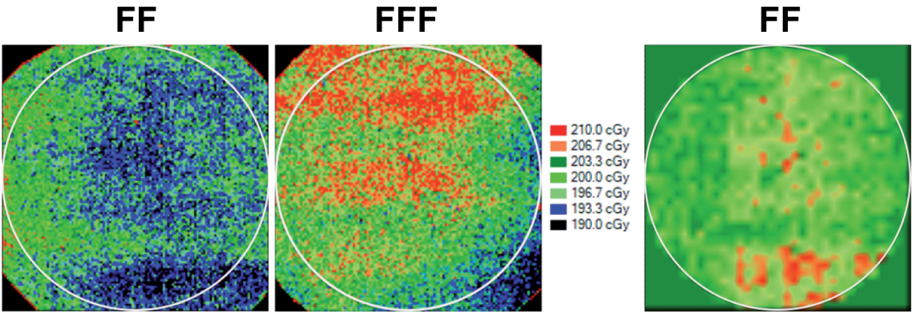

FFF

Figure 1. Experimental set-up and dose verification. (A) Drawing of the custom made jig for irradiation. (B) Color wash dose distribution for FFF (top) and FF (bottom) beams using $8 \times 8$ or $20 \times 20 \mathrm{~cm}$ irradiation field respectively. The center of the irradiation dish (FFF) or the center of the jig (FF) was positioned at the isocenter of the beam. A, anterior; P, posterior; R, right; L, left; H, head; F, feet. (C) Dose uniformity assessed using EBT3 film dosimetry (left) and difference map between delivered and planned dose (right) for FF and FFF beam. The circle indicates the $80 \%$ area of the dish.

from these damage distributions, an estimate of the RBE for initial DSB induction can be derived, from the ratio of the DNA DSB yield for a test radiation to that for the reference radiation (Hsiao and Stewart 2008). The test radiation in this work was the commonly used ${ }^{60} \mathrm{Co}$ photon spectrum.

\section{Results}

\section{Effect of high dose rate}

First we compared clonogenic survival after exposure to a standard clinical beam dose rate $(4 \mathrm{~Gy} / \mathrm{min})$ or to HDR irradiation $(24 \mathrm{~Gy} / \mathrm{min})$ in the absence of the flattening filter. Therefore, the dose rates differed in pulse repetition frequency (PRF), while dose per pulse (DPP $=0.13 \mathrm{cGy} /$ pulse) was constant, which resulted in a shorter delivery time for the HDR irradiation setup. Tumor cells were selected from a variety of organs to cover several cancer sites. No differences in tumor cell survival were observed upon irradiation for all cancer cell lines (Figure 2A). In addition, we extended our investigations on the effect of HDR irradiation on human non-tumorigenic lung and breast epithelial cells. Similar to what we observed in all tumor lines, there was no difference in cell survival between HDR and a standard dose rate of $4 \mathrm{~Gy} / \mathrm{min}$ (Figure 2B).

\section{Effect flattening filter removal}

Monte Carlo simulations showed that within the central axis of the radiation fields, the beam without flattening filter (FFF) had an estimated RBE for DSB induction that exceeded the beams with flattening filter (FF) by only $3 \%$. This value is expected to lead to negligible differences in biological damage for both photon beam modalities. To investigate if the biological effect on cell survival of FFF irradiation is indeed similar, cells were exposed to $4 \mathrm{~Gy} / \mathrm{min}$ with (FF) or without flattening filter (FFF). Neither for the tumor cells (Figure 3A), nor for the normal epithelial cells (Figure 3B), significant effects on cell survival were observed.

\section{DNA repair deficiency}

Since cell lines with low $\alpha / \beta$ ratio are more sensitive to variations in $\mathrm{RBE}$ of the ionizing irradiation to which they 
(A)
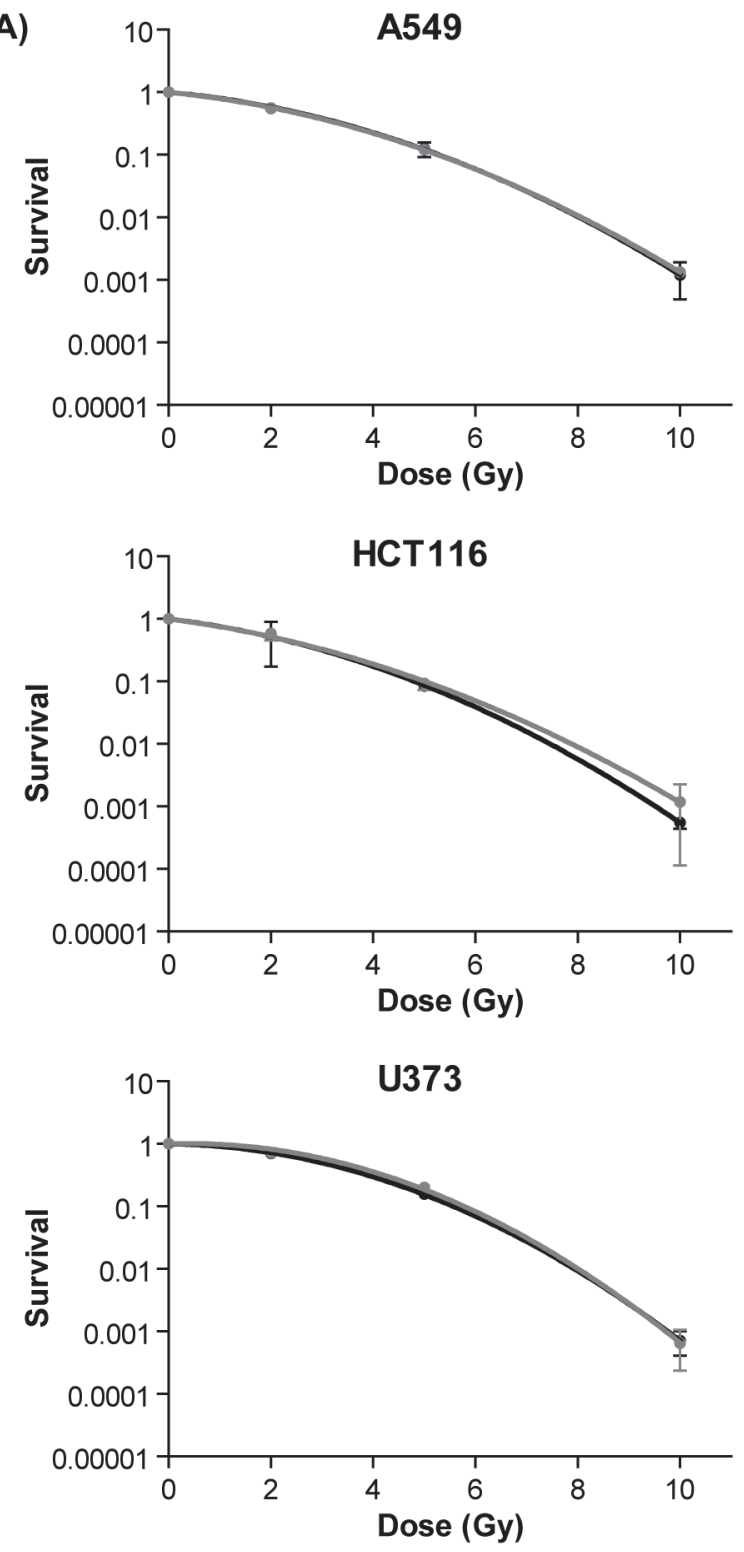

(B)

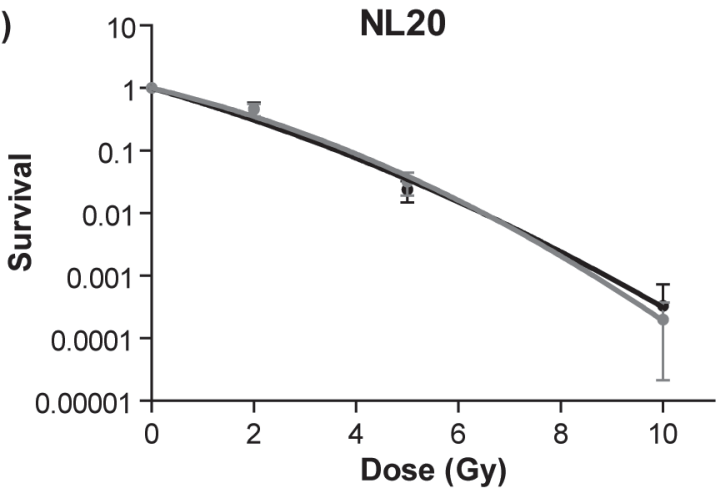

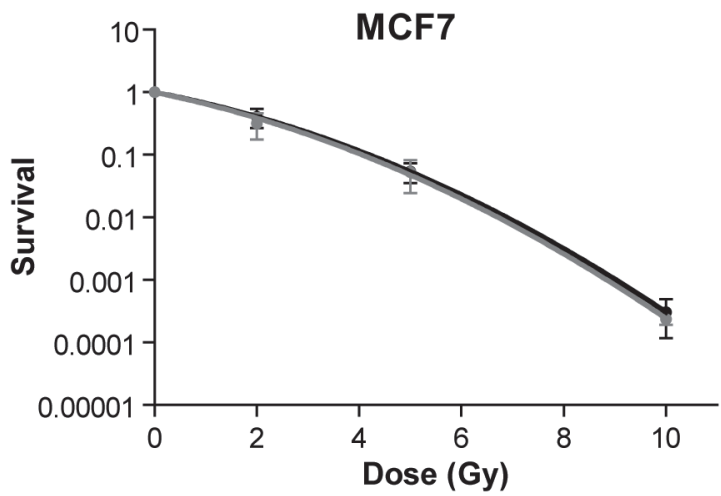

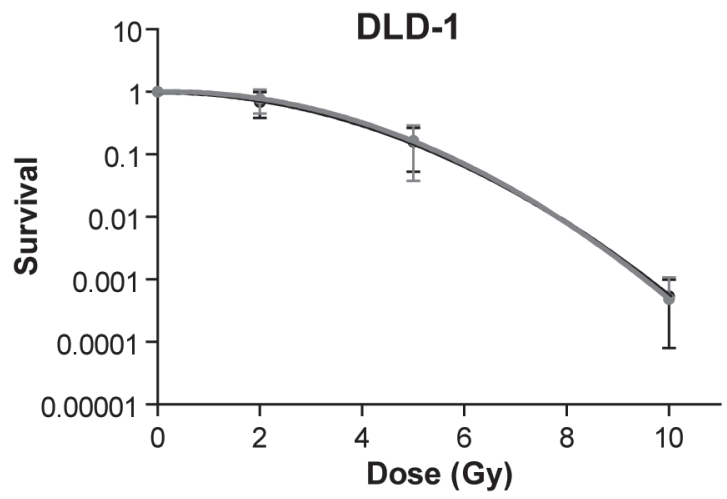

- 4 Gy/min FFF

- $24 \mathrm{~Gy} / \mathrm{min} \mathrm{FFF}$

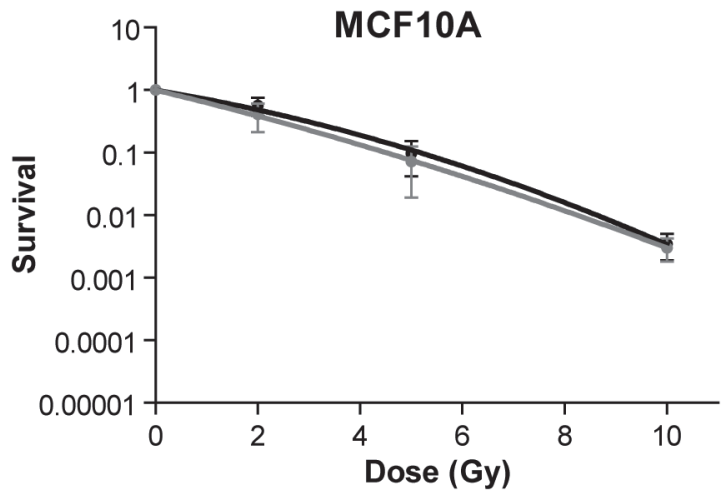

Figure 2. Effect of high dose rate irradiation on clonogenic survival for tumor and non-tumorigenic cells. Clonogenic survival for human tumor (A) and non-tumorigenic immortalized epithelial (B) cells from different tissues for low (4 Gy/min, black) and high (24 Gy/min, gray) dose rate irradiation with flattening filter removed (FFF). Data represent the mean \pm SD of at least three independent experiments.

are exposed to, we investigated whether HDR FFF irradiation had a more pronounced effect on survival of DNA repair deficient cells. For this purpose, we assessed clonogenic survival capacity in NHEJ or HR repair deficient human colorectal or Chinese hamster ovary (CHO) carcinoma cells compared to their wild-type isogenic controls.
A NER deficient carcinoma cell line was included as control for single-strand break repair deficiency (Figure 4). As expected, both human and hamster carcinoma cell lines deficient for NHEJ were more radiosensitive compared to the wild type cells. In the HR deficient cells, radiosensitization was less pronounced for the human cells, while 
(A)
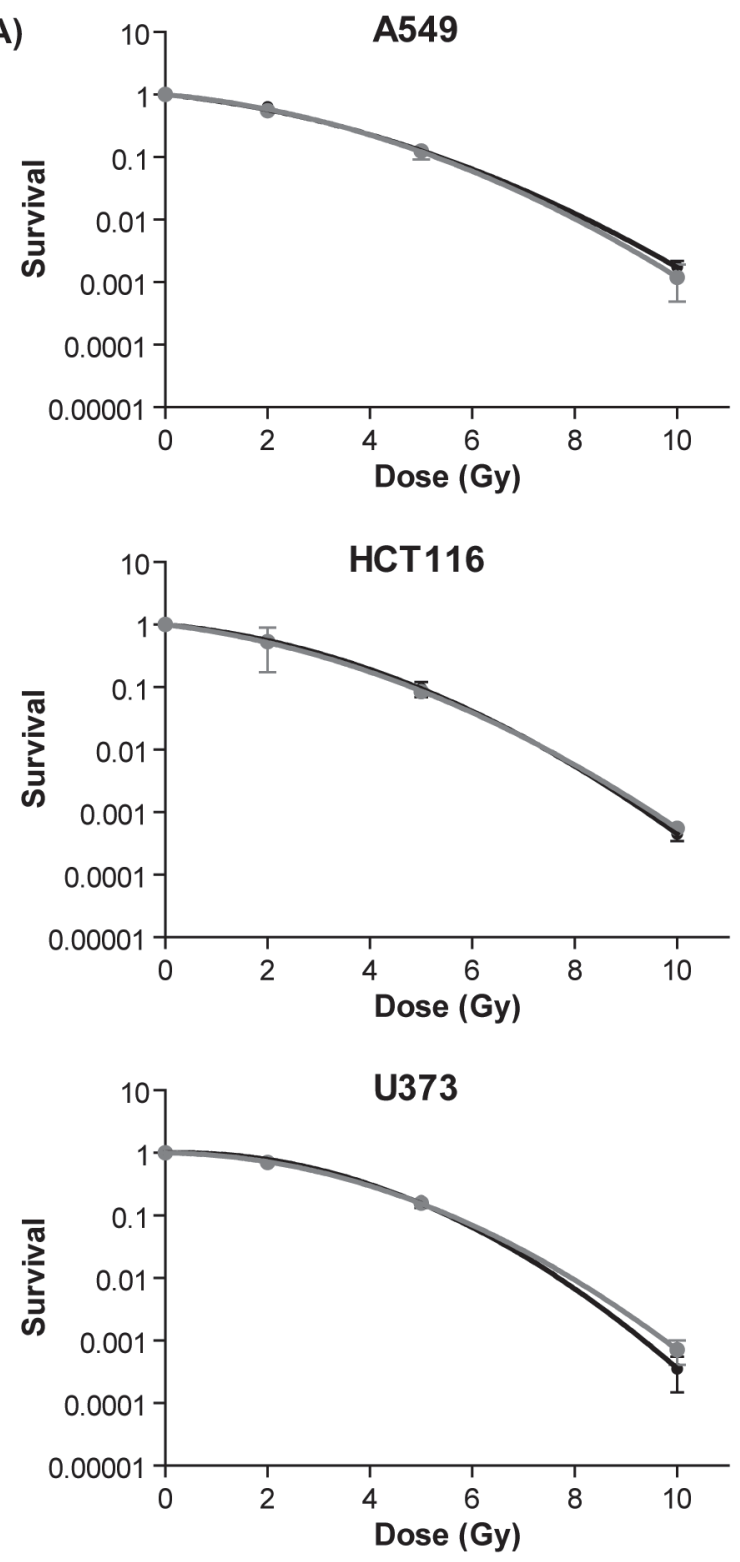

(B)

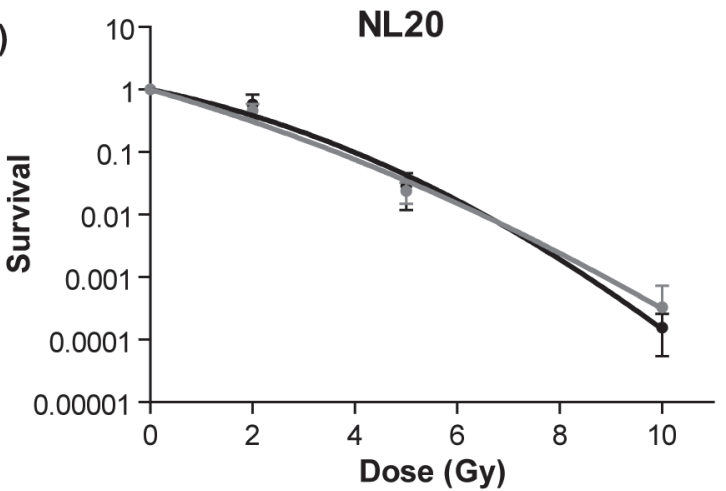

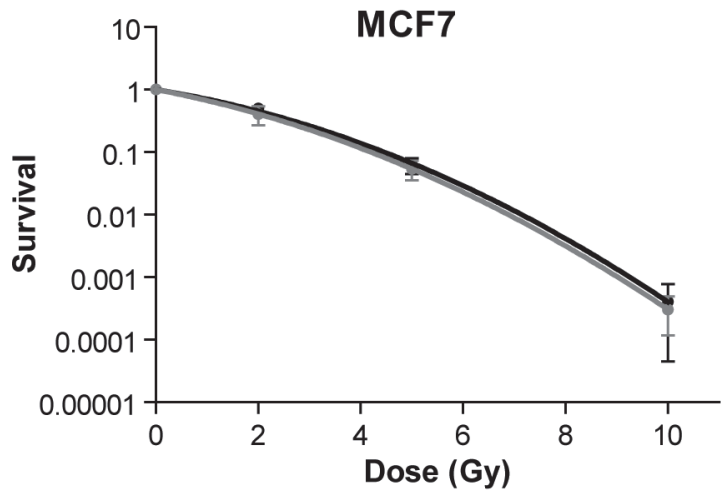

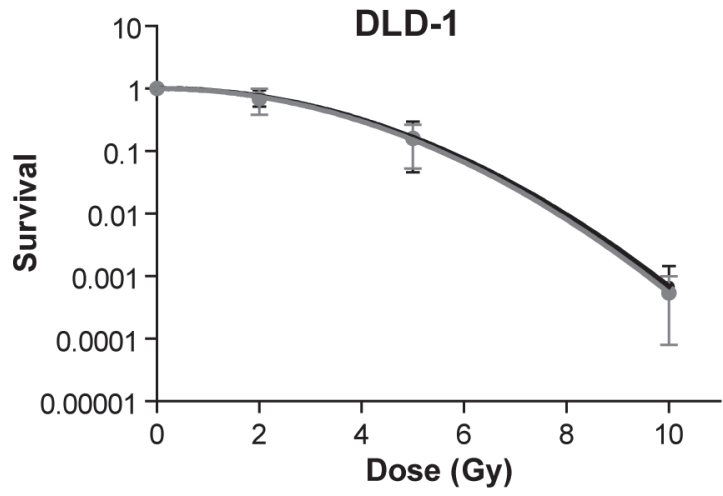

- $4 \mathrm{~Gy} / \mathrm{min} \mathrm{FF}$

- 4 Gy/min FFF

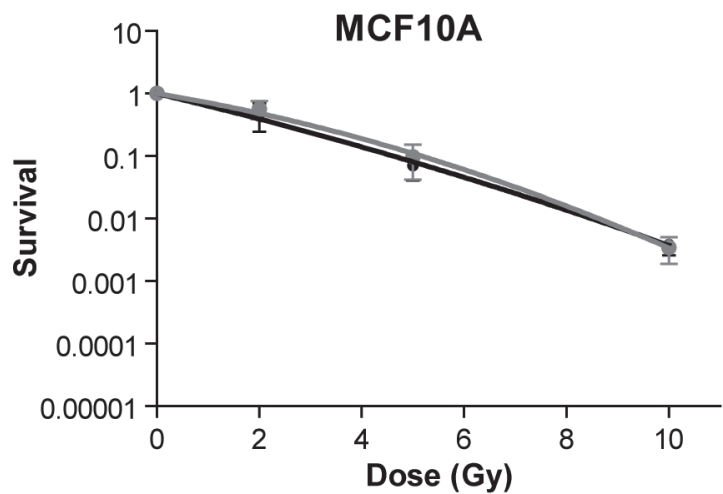

Figure 3. Effect of flattening filter free irradiation on clonogenic survival for tumor and non-tumorigenic cells. Clonogenic survival for human tumor (A) and non-tumorigenic immortalized epithelial (B) cells from different tissues for conventional flattened beam (FF, black) and flattening filter free (FFF, gray) irradiation keeping the dose rate constant $(4 \mathrm{~Gy} / \mathrm{min}$ ). Data represent the mean $\pm \mathrm{SD}$ of at least three independent experiments.

no difference was found for the hamster carcinoma cells. No difference in radiosensitivity was observed for the NER deficient cells compared to the parental cell line. Although differences in radiosensitivity were observed for DNA repair deficient cells, HDR irradiation did not alter their survival in either direction compared to normal dose rates (Figure 4). Additionally, flattening filter removal did not result in a decreased survival compared to conventional filtered beam irradiation (Supplementary Figure 1, available online at http://informahealthcare.com/abs/doi 
(A) HCT116 parental vs. DNA-PKcs-/- (NHEJ)

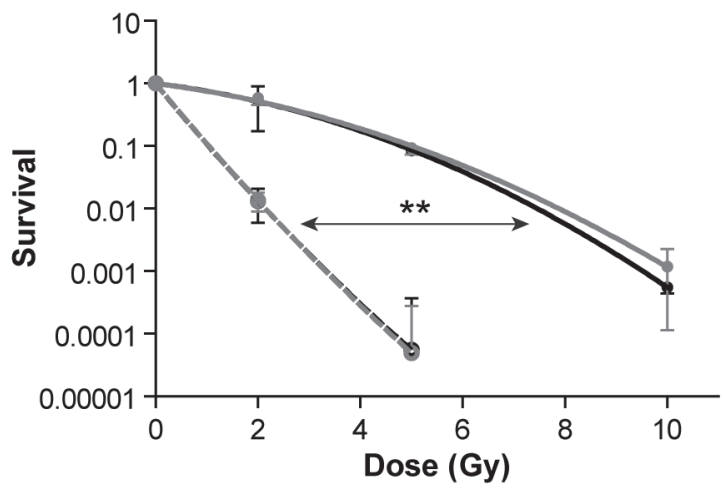

(B)

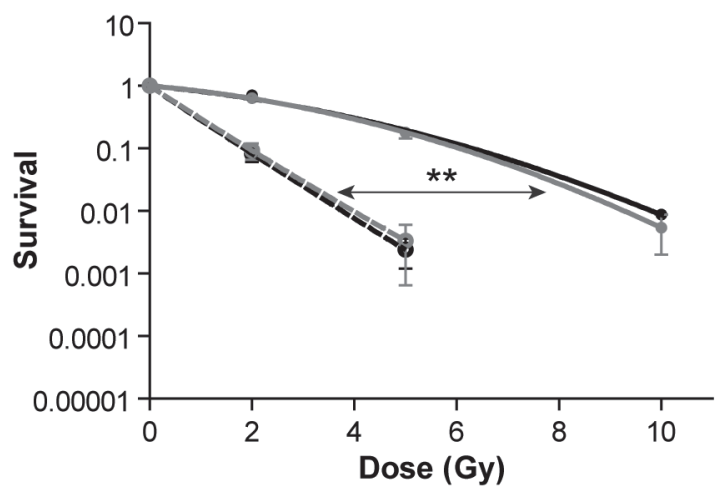

AA8 wild type vs. UV5 (XPD-/- NER)

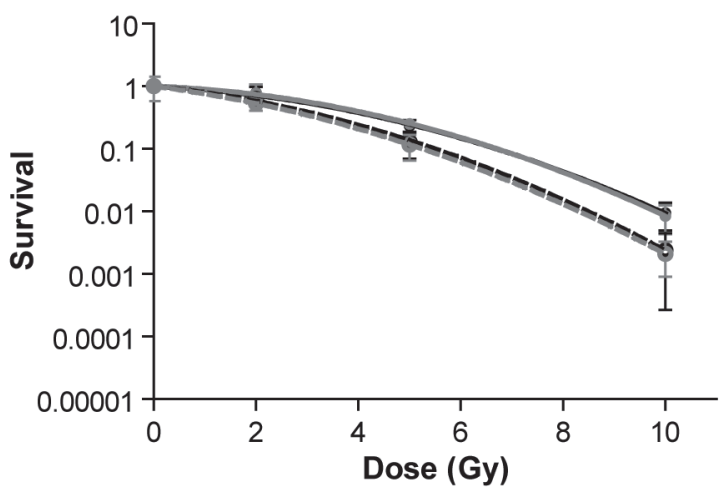

DLD parental vs. BRCA2-I- (HR)

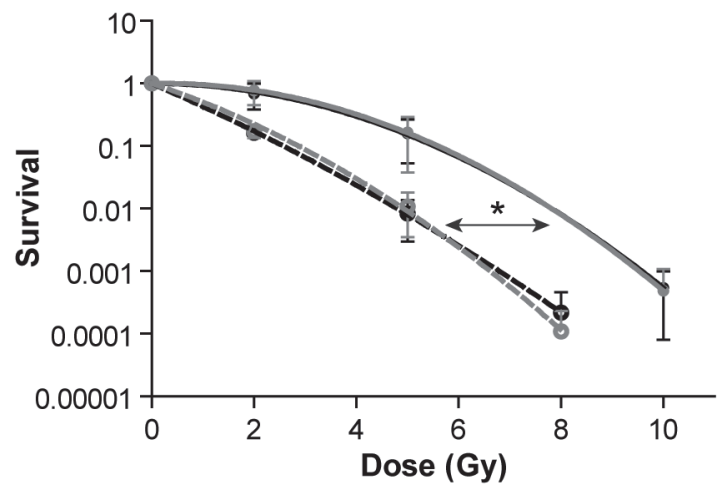

AA8 wild type vs. IRS1sf (XRCC3-I- HR)

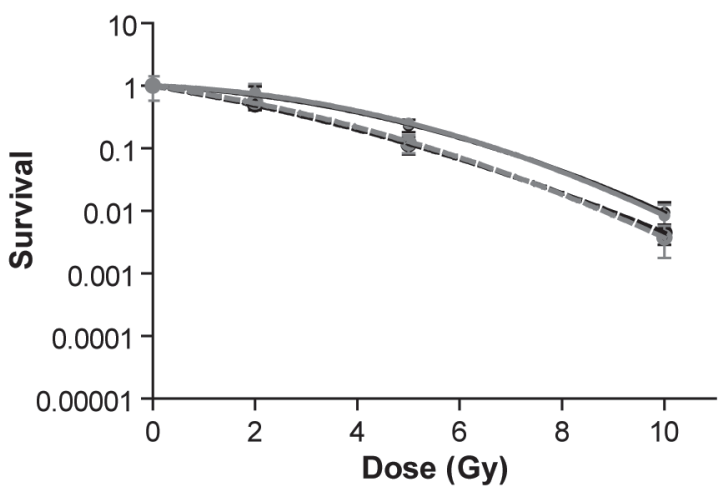

- 4 Gy/min FFF

- $24 \mathrm{~Gy} / \mathrm{min}$ FFF

Figure 4. Effect of high dose rate irradiation on clonogenic survival for DNA repair deficient carcinoma cells. Clonogenic survival for human colorectal (A) or Chinese hamster ovary (B) DNA repair deficient carcinoma cells (dashed line) compared to wild type cells (full line) for low ( $4 \mathrm{~Gy} / \mathrm{min}$, black) and high ( $24 \mathrm{~Gy} / \mathrm{min}$, gray) dose rate irradiation with flattening filter removed (FFF). Data represent the mean $\pm \mathrm{SD}$ of at least three independent experiments. Arrows indicate significant differences between LQ fitted curves based on the Extra sum-of-squares F test. * $p<0.05$, $* * p<0.01$.

/10.3109/09553002.2015.1068457) in DNA repair deficient cells.

\section{Discussion}

Instantaneous HDR (24 Gy/min) or FFF ( $4 \mathrm{~Gy} / \mathrm{min}$ FF versus FFF) irradiation did not result in altered clonogenic survival. This was observed for tumor cell lines originating from different sites (lung, breast, colon and brain) and for non-tumorigenic human epithelial cells (lung and breast). Furthermore and for the first time, this was shown as well for homologous and non-homologous end joining repair deficient human colorectal or Chinese hamster ovary carcinoma cells. Additionally, Monte Carlo simulations estimated only a $3 \%$ increase of RBE for DSB induction from FFF beams compared to FF beams, confirming the equal clonogenic survival for the different beams. Our results for the tumor and non-tumorigenic human cells are in agreement with recent experimental reports (Supplementary Table I, available online at http://informahealthcare.com/abs/doi/ 10.3109/09553002.2015.1068457), which applied however a different beam energy (6 MV) and dose rates (Karan et al. 2013, King et al. 2013, Lasio et al. 2014), and theoretical calculations (Ling et al. 2010). In contrast, Lohse et al. (2011) 
did observe enhanced glioblastoma cell killing after removal of the flattening filter (10 MV $4 \mathrm{~Gy} / \mathrm{min}$ ) of cells exposed to doses of 10 Gy and higher.

Importantly, our results indicated also no difference in clonogenic survival after exposure to $4 \mathrm{~Gy} / \mathrm{min}$ FF versus $24 \mathrm{~Gy} / \mathrm{min}$ FFF irradiation. Consistent with our findings, Verbakel et al. (2013) found equal biological effects after increasing the instantaneous dose rate from a $6 \mathrm{~Gy} / \mathrm{min} \mathrm{FF}$ to $24 \mathrm{~Gy} / \mathrm{min}$ FFF $10 \mathrm{MV}$ schedule and similar effects were observed upon fractionated irradiation. Sorensen et al. (2011) also reported no dependence of cell survival on the instantaneous dose rate, although no FFF beams were used. In the latter study, high dose rates were obtained using regular FF 6 MV beams for which the distance to the source was varied resulting in dose rates of 5, 10 and $30 \mathrm{~Gy} / \mathrm{min}$. Our results obtained using similar settings however are in contrast with the data from Lohse et al. (2011), who reported increased radiation efficacy with increasing dose rates. Lasio et al. (2014), using the same cell lines, reported contradictory results as well.

The biological outcome of dose rate experiments is dependent on successful repair of sublethal DNA damage during and immediately after irradiation (Steel et al. 1987). This has shown to be especially important for low dose rate irradiation. As radiation dose delivery time increases, a number of biological processes, such as DNA repair, proliferation, reoxygenation and cell cycle redistribution might already take place during irradiation, obscuring the observed radiation response (Steel et al. 1986). This implies that during high dose rate irradiation more residual DNA damage is present at the end of treatment compared to low dose rate which would be exacerbated by DNA repair deficiencies. We therefore investigated if HDR FFF irradiation would have more pronounced effects on survival of NHEJ, HR or NER deficient human colorectal or Chinese hamster ovary carcinoma cells. As expected, both NHEJ and HR deficient cells were more radiosensitive compared to their wild type control cell lines, with an even more pronounced difference for the NHEJdeficient cells. This could be explained by the differential contribution of NHEJ and HR to radiation-induced repair, with NHEJ being the predominant repair pathway throughout the cell cycle (Rothkamm et al. 2003). Additionally, Ku70 deficiency resulted in a more radiosensitive phenotype compared to DNA-PKcs repair deficient cells (Hu and Hill 1996). Furthermore, the AA8 IRS1sf HR deficient cell line demonstrates only a marginal radiosensitive effect on survival likely due to the fact that these cells are only partially defective in HR (Rothkamm et al. 2003). As expected, NER deficient UV5 cells were not more radiosensitive than wild type cells, mainly because NER is involved in the repair of bulky lesions or DNA adducts after UV irradiation or cisplatin treatment rather than dsDNA break repair (Shuck et al. 2008). Whereas enhanced radiosensitivity was observed in DNA repair deficient cells, neither HDR irradiation nor flattening filter removal had an additional effect on cell survival in any of these cell lines. A differential sensitization effect upon increasing dose rate $(0.09-10 \mathrm{~Gy} / \mathrm{min})$ has been observed to correlate with deficiency of NHEJ pathway components. DNA-PKcs deficiency resulted in a 4 -fold increased surviving fraction at 2 Gy (SF2) for high dose rate irradiation compared to only a marginal effect for Ku70 deficient cells (Hu and Hill 1996).

First clinical studies have also demonstrated the feasibility and safety of, e.g., stereotactic body radiotherapy (SBRT) treatment in FFF mode reaching dose rates up to $24 \mathrm{~Gy} / \mathrm{min}$ (Scorsetti et al. 2011, Mancosu et al. 2012, Prendergast et al. 2013, Wang et al. 2014). Our study confirms that FFF high dose rate beams have no additional detrimental effects on tumor and more importantly on normal tissue cell survival. Furthermore, no difference in effect on survival was observed for DNA repair deficient cells. Additionally, preliminary experiments using fractionated irradiation have provided similar results (Karan et al. 2013, Verbakel et al. 2013).

\section{Conclusion}

Overall, these data indicate that from a radiobiological point of view FFF high dose rate irradiation at clinical relevant doses is safe and could be implemented in daily clinical practice.

\section{Acknowledgements}

The work described here is part of a cooperation agreement with Varian Medical Systems AG, Cham, Switzerland.

\section{Declaration of interest}

The authors report no conflict of interest. The authors alone are responsible for the content and writing of the paper.

\section{References}

Bedford JS, Mitchell JB. 1973. Dose-rate effects in synchronous mammalian cells in culture. Radiat Res 54:316-327.

Georg D, Knoos T, Mcclean B. 2011. Current status and future perspective of flattening filter free photon beams. Medical Phys 38: 1280-1293.

Goodhead DT. 1994. Initial events in the cellular effects of ionizing radiations: Clustered damage in DNA. Int J Radiat Biol 65:7-17.

Hsiao Y, Stewart RD. 2008. Monte Carlo simulation of DNA damage induction by x-rays and selected radioisotopes. Phys Med Biol 53:233-244.

Hu Q, Hill RP. 1996. Radiosensitivity, apoptosis and repair of DNA double-strand breaks in radiation-sensitive Chinese hamster ovary cell mutants treated at different dose rates. Radiat Res 146:636-645.

Karan T, Moiseenko V, Gill B, Horwood R, Kyle A, Minchinton AI. 2013. Radiobiological effects of altering dose rate in filter-free photon beams. Phys Med Biol 58:1075-1082.

Kawrakow I. 2000. Accurate condensed history Monte Carlo simulation of electron transport. I. EGSnrc, the new EGS4 version. Med Phys 27:485-498.

King RB, Hyland WB, Cole AJ, Butterworth KT, Mcmahon SJ, Redmond KM, Trainer C, Prise KM, Mcgarry CK, Hounsell AR. 2013. An in vitro study of the radiobiological effects of flattening filter free radiotherapy treatments. Phys Med Biol 58:N83-94.

Kirkby C, Field C, Mackenzie M, Syme A, Fallone BG. 2007. A Monte Carlo study of the variation of electron fluence in water from a $6 \mathrm{MV}$ photon beam outside of the field. Phys Med Biol 52:3563-3578.

Kry SF, Popple R, Molineu A, Followill DS. 2012. Ion recombination correction factors ( $\mathrm{P}(\mathrm{ion})$ ) for Varian TrueBeam high-dose-rate therapy beams. J Appl Clin Med Phys 13:3803.

Lambin P, Wouters BG. 2004. Molecular explanation of variation in the a/b ratio. ESTRO Newsletter 58:13.

Lasio G, Guerrero M, Goetz W, Lima F, Baulch JE. 2014. Effect of varying dose-per-pulse and average dose rate in X-ray beam irradiation on cultured cell survival. Radiat Environ Biophys 53:671-676.

Ling CC, Gerweck LE, Zaider M, Yorke E. 2010. Dose-rate effects in external beam radiotherapy redux. Radiother Oncol 95:261-268. 
Liu HH, Verhaegen F. 2002. An investigation of energy spectrum and lineal energy variations in mega-voltage photon beams used for radiotherapy. Radiat Prot Dosimetry 99:425-427.

Lohse I, Lang S, Hrbacek J, Scheidegger S, Bodis S, Macedo NS, Feng J, Lutolf UM, Zaugg K. 2011. Effect of high dose per pulse flattening filter-free beams on cancer cell survival. Radiother Oncol 101:226-232.

Mancosu P, Castiglioni S, Reggiori G, Catalano M, Alongi F, Pellegrini C, Arcangeli S, Tozzi A, Lobefalo F, Fogliata A, Navarria P, Cozzi L, Scorsetti M. 2012. Stereotactic body radiation therapy for liver tumours using flattening filter free beam: Dosimetric and technical considerations. Radiat Oncol 7:16.

Prendergast BM, Dobelbower MC, Bonner JA, Popple RA, Baden CJ, Minnich DJ, Cerfolio RJ, Spencer SA, Fiveash JB. 2013. Stereotactic body radiation therapy (SBRT) for lung malignancies: Preliminary toxicity results using a flattening filter-free linear accelerator operating at 2400 monitor units per minute. Radiat Oncol 8:273.

Reniers B, Liu D, Rusch T, Verhaegen F. 2008. Calculation of relative biological effectiveness of a low-energy electronic brachytherapy source. Phys Med Biol 53:7125-7135.

Rothkamm K, Kruger I, Thompson LH, Löbrich M. 2003. Pathways of DNA double-strand break repair during the mammalian cell cycle. Mol Cell Biol 23:5706-5715.

Scorsetti M, Alongi F, Castiglioni S, Clivio A, Fogliata A, Lobefalo F, Mancosu P, Navarria P, Palumbo V, Pellegrini C, Pentimalli S, Reggiori G, Ascolese AM, Roggio A, Arcangeli S, Tozzi A, Vanetti E, Cozzi L. 2011. Feasibility and early clinical assessment of flattening filter free (FFF) based stereotactic body radiotherapy (SBRT) treatments. Radiat Oncol 6:113.

\section{Supplementary material available online}

Supplementary Figure 1 and Table I. available online at http://informahealthcare.com/abs/doi/10.3109/09553002. 2015.1068457
Shuck SC, Short EA, Turchi JJ. 2008. Eukaryotic nucleotide excision repair: From understanding mechanisms to influencing biology. Cell Res 18:64-72.

Sorensen BS, Vestergaard A, Overgaard J, Praestegaard LH. 2011. Dependence of cell survival on instantaneous dose rate of a linear accelerator. Radiother Oncol 101:223-225.

Steel GG, Deacon JM, Duchesne GM, Horwich A, Kelland LR, Peacock JH. 1987. The dose-rate effect in human tumour cells. Radiother Oncol 9: 299-310.

Steel GG, Down JD, Peacock JH, Stephens TC. 1986. Dose-rate effects and the repair of radiation damage. Radiother Oncol 5:321-331.

Syme A, Kirkby C, Mirzayans R, Mackenzie M, Field C, Fallone BG. 2009. Relative biological damage and electron fluence in and out of a 6 MV photon field. Phys Med Biol 54:6623-6633.

Verbakel WF, Van Den Berg J, Slotman BJ, Sminia P. 2013. Comparable cell survival between high dose rate flattening filter free and conventional dose rate irradiation. Acta Oncol 52:652-657.

Verhaegen F, Seuntjens J. 2003. Monte Carlo modelling of external radiotherapy photon beams. Phys Med Biol 48:R107-164.

Wang JZ, Li XA, D'souza WD, Stewart RD. 2003. Impact of prolonged fraction delivery times on tumor control: A note of caution for intensity-modulated radiation therapy (IMRT). Int J Radiat Oncol Biol Phys 57:543-552.

Wang PM, Hsu WC, Chung NN, Chang FL, Jang CJ, Fogliata A, Scorsetti M, Cozzi L. 2014. Feasibility of stereotactic body radiation therapy with volumetric modulated arc therapy and high intensity photon beams for hepatocellular carcinoma patients. Radiat Oncol 9:18. 